\title{
The Diagnostic Sensitivity, Specificity and Reproducibility of the Clinical Physical Examination Signs in Patients of Diabetes Mellitus for Making Diagnosis of Peripheral Neuropathy
}

\author{
Bharati Taksande $^{\mathrm{a}, \mathrm{b}}$, Saima Ansaria ${ }^{\mathrm{a}}$, Ashish Jaikishan ${ }^{\mathrm{a}}$, Vikas Karwasara ${ }^{\mathrm{a}}$
}

\begin{abstract}
Background: Diabetes mellitus is one of the most common chronic diseases. Prevalence of neuropathy in type 1 and type 2 diabetes is as high as $66 \%$ and $59 \%$ respectively. As underdiagnosis of neuropathy is common in clinical practice, we plan to identify the symptoms and signs which either alone or in combination have the best predictive value. The research question for the current study is that in patients with diabetes mellitus (type 1 and type 2) what is the diagnostic accuracy of physical signs in the diagnosis of peripheral neuropathy, as compared to the electro-diagnostic test (nerve conduction studies, NCS) as a reference standard and the reliability of these physical signs as a bedside examination tool.
\end{abstract}

Methods: The study was conducted at Mahatma Gandhi Institute of Medical Sciences, Sevagram. For a period of two months (May - June 2009) we prospectively identified all consecutive patients of diabetes mellitus (type 1 and type 2) admitted to the medicine wards. The clinical signs were evaluated in each of the two lower limbs of all patients by two observers blinded to each other. And then patients underwent electrodiagnostic studies done by the trained technician and interpreted by a trained physician.

Results: Absent ankle reflex was the most sensitive sign to detect neuropathy of any type. Impairment of vibration had the highest specificity. None of the physical signs alone had sufficiently high positive likelihood ratio to significantly increase the post-test probability of neuropathy with the sign being positive. Similarly none of the signs by itself had a low negative likelihood ratio to be able to rule out neuropathy. The interobserver reproducibility of the physical signs was moderate to poor. Impaired vibration test had a fair agreement between the two observers.

\footnotetext{
Manuscript accepted for publication August 24, 2010

${ }^{a}$ Department of Medicine and Department of physiology, Mahatma Gandhi Institute of Medical Sciences, Sewagram, Maharashtra, India

${ }^{\mathrm{b} C}$ Corresponding author: Bharati Taksande, Department of Medicine, Mahatma Gandhi Institute of Medical Sciences, Sewagram,

Maharashtra, India. Email: bharati.taksande@gmail.com
}

doi:10.4021/jem101e
Conclusions: Our study implies the annual foot examination of the diabetes irrespective of the duration of the diabetes. In clinical practice, however electrophysiological tests should not replace clinical examination because NCS has many pitfalls and the interpretation of the results should be done in the context of clinical data.

Keywords: Diabetes; Peripheral neuropathy; Physical signs; Nerve conduction study; Electrophysiological studies

\section{Introduction}

Diabetes mellitus is one of the most common chronic diseases. Indeed with over 40 million people with diabetes, India is already recognized as the "diabetic capital" of the world [1]. Diabetes is associated with various neuropathy syndromes. Prevalence of neuropathy in type 1 and type 2 diabetes is as high as $66 \%$ and $59 \%$ respectively. It may manifest as polyneuropathy, mononeuropathy, and/or autonomic neuropathy. Diabetic neuropathy leads to diabetic foot, a complication which could result in limb amputations. It is known that the risk of limb amputation is 12 times higher in diabetics, as compared to non-diabetics [2]. The progression of neuropathy can be reduced by early detection and intervention [3]. Diabetic neuropathy may be asymptomatic, or may present with either positive or negative sensory phenomenon. Although periodic screening for neuropathy is recommended in all diabetics, this screening is based on assessment of clinical symptoms and signs. Electro-diagnosis of diabetic neuropathy is a reference standard for diagnosis of diabetic neuropathy, but it is expensive, and its availability is limited.

Diabetic neuropathy cannot be diagnosed without careful examination because diabetic neuropathy may be asymptomatic in a number of patients. The diagnosis of diabetic neuropathy requires at least one of the five criteria: a) symptoms, b) signs, c) electrodiagnostic test, d) quantitative sensory, and e) autonomic testing. However for clinical practice two of these five criteria have been recommended [4]. Underdiagnosis or misdiagnosis of diabetic neuropathy in clinical practice has been emphasized in GOAL A1C study in 
which 7000 patients were evaluated and only $38 \%$ with mild and $61 \%$ with severe neuropathy were detected. This study highlighted the importance of education of physician in diagnosing diabetic neuropathy [5]. Another study evaluated the efficacy of neuropathy symptom score/neuropathy disability score (NSS/NDS), Michigan Neuropathy Screening Instrument (MNSI), vibration perception threshold (VPT) and $24010 \mathrm{~g}$ monofilament examination in the diagnosis of diabetic peripheral neuropathy (DPN) and finally concluded that MNSI is a rapid, simple and reliable test for screening DPN in both diabetes clinics and epidemiological surveys [6].

However the literature indicates that symptoms alone have relatively poor diagnostic accuracy in predicting the presence of polyneuropathy, signs are better predictors of polyneuropathy than symptoms; and single abnormalities on examination are less sensitive than multiple abnormalities in predicting the presence of polyneuropathy. The diagnostic accuracy of individual symptoms and signs has been studied in only a limited number of studies [7]. As underdiag- nosis of neuropathy is common in clinical practice, we plan to identify the symptoms and signs which either alone or in combination have the best predictive value. The research question for the current study is that in patients with diabetes mellitus (type 1 and type 2) what is the diagnostic accuracy of physical signs in the diagnosis of peripheral neuropathy, as compared to the electro-diagnostic test (nerve conduction studies) as a reference standard and the reliability of these physical signs as a bedside examination tool.

\section{Materials and Methods}

\section{Setting}

The study was conducted at Mahatma Gandhi Institute of Medical Sciences, Sevagram, a rural medical college in Maharashtra. It is a 648 bed teaching institution. About 6500 patients are admitted to the internal medicine ward each year and nearly 3 - 4 patients of diabetes mellitus are admitted

Table 1. Clinical Examination Index Tests Used in the Current Study

\begin{tabular}{|c|c|c|}
\hline Modality tested & Test procedure & $\begin{array}{l}\text { Interpretation of abnormal } \\
\text { test }\end{array}$ \\
\hline $\begin{array}{l}\text { Cutaneous } \\
\text { sensations }\end{array}$ & $\begin{array}{l}\text { Equipment: } 10 \mathrm{~g} \text { Semmes Weinstein monofilament } \\
\text { Procedure: Cutaneous touch sensation tested on ten sites of spirit } \\
\text { alcohol wiped foot. These sites were i) dorsal surface of the foot } \\
\text { between the base of the first and second toes, ii) first toe, iii) third } \\
\text { toe, iv) fifth toe, v) the first metatarsal head, vi) third metatarsal } \\
\text { head, vii) fifth metatarsal head, viii) medial midfoot, ix) lateral } \\
\text { midfoot and x) heel. } \\
\text { The monofilament was pressed perpendicular to the test site with } \\
\text { enough pressure to bend the monofilament for } 1 \text { sec. Patients was } \\
\text { asked to answer "Yes" or "No", when felt or did not feel the press } \\
\text { of the monofilament, respectively. }\end{array}$ & $\begin{array}{l}\text { If a patient did not perceive } \\
\text { the filament at more than } 4 \\
\text { out of } 10 \text { sites, then the test } \\
\text { was considered abnormal. }\end{array}$ \\
\hline Vibration test & $\begin{array}{l}\text { Equipment: } 128 \text { hertz vibration fork } \\
\text { Procedure: The stimulus was applied over the distal phalanx of the } \\
\text { large toe. The patient reported whether they felt vibration sense } \\
\text { and then reported when it stoped in order to assess the minimal } \\
\text { threshold to perceive the stimulus. }\end{array}$ & $\begin{array}{l}\text { If the patient did not perceive } \\
\text { the vibration it would be } \\
\text { labeled as absent vibration } \\
\text { sensation or impaired } \\
\text { vibration. }\end{array}$ \\
\hline Ankle reflex & $\begin{array}{l}\text { Equipment: Standard percussion hammer } \\
\text { Procedure: The ankle reflex was elicited by holding the relaxed foot } \\
\text { with one hand and striking the Achilles tendon with the hammer } \\
\text { with other hand, and noting plantar flexion. }\end{array}$ & $\begin{array}{l}\text { A positive result would be the } \\
\text { jerking of the foot towards } \\
\text { its plantar surface (plantar } \\
\text { flexion) and the contraction of } \\
\text { calf muscles and its absence } \\
\text { was labeled as absent ankle } \\
\text { reflex. }\end{array}$ \\
\hline
\end{tabular}


each day. Although much larger number of patients with diabetes seek out-patient care, we limited our study to inpatients.

\section{Study design: prospective diagnostic study}

For a period of two months (May - June 2009) we prospectively identified all consecutive patients of diabetes mellitus (type 1 and type 2) admitted to the medicine wards. The eligible patients included all those who had been diagnosed with diabetes mellitus by their treating physicians either prior to or during hospital admission. Patients who denied consent, unconscious, who cannot themselves inform about their symptoms, or who were critically ill that they cannot be transferred for performance of nerve conduction velocity were excluded. No other exclusion criteria were used.

\section{Ascertainment of the index tests}

The clinical signs were evaluated in each of the two lower limbs of all patients, and each limb was considered as a separate unit of observation. One medicine resident, who screened all consecutive admissions to identify the patients with Diabetes mellitus, provided a list of all eligibles to the two observers - a medical student (SA) and a physician with four years of experience (AJ). These two observers were trained prior to the start of the study in the exact techniques to be used for clinical examination. Each of the two observers examined the patients blinded to each other and independently interpreted results of clinical examination. Three tests performed on clinical examination were touch sensation over lower limb, vibration sensation and ankle reflex. The method and interpretation of these clinical tests are provided in Table1. All the tests were coded as 0 for normal and 1 for an abnormal result. These variables were collected in a blind and independent manner, and prior to the electrodiagnostic studies. If any one of above mentioned test was abnormal patient was considered to have peripheral neuropathy.

\section{Ascertainment of the reference method}

All patients, after the physical signs were elicited, underwent electrodiagnostic studies (nerve conduction studies). The technique is most sensitive for detecting early changes; nerve conduction velocities (NCV) can be used prior to the development of clinical signs and symptoms and it is helpful for predicting new ulceration $[8,9]$. The electrodiagnostic study was performed on the same day as the performance of the index test. The nerve conduction studies were done by trained technician on RMS-EMG EP machine and the results were interpreted by a trained physician. Both the technician as well as the physician were blinded to the results of the index test. Nerve conduction studies were performed on bilateral tibial nerves in lower limb for motor neuropathy and sural in lower limb for sensory neuropathy, with surface recording, using the standardized technique. The following parameters on nerve conduction study were evaluated: 1) DML (Distal Motor Latency), 2) CMAP (Compound muscle action potential), peak to peak amplitude, 3) FWL (F-wave Latency): mean of individual latencies from each F-wave set. (Number of latencies is the minimum of 20 and number of F-waves detected in 40, as not all $\mathrm{F}$-wave traces will have $\mathrm{F}$-wave), 4) SNAP (sensory nerve action potential) peak to base amplitude, 5) conduction velocity (CV). Based on the results of the above parameters, the trained physician made a diagnosis of diabetic neuropathy. Accordingly, sensory neuropathy was defined if any one or more than one of the findings was present in sural nerve, i.e., prolonged sensory latency $(>3.5$ $\mathrm{ms})$, reduced SNAP $(<7.5$ microvolt) or reduced conduction velocity $(<40 \mathrm{~m} / \mathrm{sec})$. Motor neuropathy was defined if any one or more than one of the findings was present in tibial nerve, i.e., prolonged DML $(>3.5 \mathrm{~ms})$, reduced CMAP $(<8$ $\mathrm{mV})$, reduced conduction velocity $(<50 \mathrm{~m} / \mathrm{sec})$ or absent or prolonged $\mathrm{F}$ wave latency $(>51 \mathrm{~ms})$.

\section{Statistical analysis}

We determined interobserver reproducibility between two observers for each physical sign. Percent agreement and kappa statistic (percent agreement beyond chance) were used as measures of reproducibility. Diagnostic accuracy was measured by the computation of the following test statistics for each symptom and sign, and combination of signs and symptoms, using standard methods: sensitivity, specificity, positive likelihood ratios (LR+), negative likelihood ratios (LR), and positive and negative predictive values. The precision of these estimates was evaluated by using $95 \%$ confidence intervals $(95 \% \mathrm{CI})$. The likelihood ratios were computed by means of sensitivity and specificity values. They indicate by how much a given test result will raise or lower the pre-test probability of the target disease.

\section{Results}

A total of 50 patients (100 limbs) were included in the study. Mean age of all patients was 63 years and $30 \%$ were females. The median duration of diabetes at the time of inclusion in the study was 42 months (range 24 to 60). The interobserver reproducibility of the physical signs was moderate to poor (kappa ranges between 0.35 and 0.53 for different physical signs (Table 2).

The diagnostic accuracy of physical signs to detect motor, sensory or mixed type of neuropathy was poor, and ranged between $25(95 \%$ CI 10.81 - 44.92) and $85(95 \%$ CI 76.24 -92.15). Absent ankle reflex was the most sensitive sign to detect neuropathy of any type, range of sensitivity $72.22(95 \%$ CI $59.21-82.91)$ to $78.95(95 \%$ CI 63.91 
Table 2. Reproducibility of Physical Signs

\begin{tabular}{llll}
\hline $\begin{array}{l}\text { Observer } 1 \text { (Medical student) vs. } \\
\text { Observer 2 (Physician) }\end{array}$ & $\begin{array}{l}\text { Impaired } \\
\text { vibration }\end{array}$ & $\begin{array}{l}\text { Impaired } \\
\text { sensation }\end{array}$ & $\begin{array}{l}\text { Absent ankle } \\
\text { reflex }\end{array}$ \\
\hline Percent agreement & 83 & 82 & 77 \\
Kappa & 0.35 & 0.53 & 0.45 \\
$95 \%$ CI & $0.11-0.60$ & $0.35-0.72$ & $0.27-0.64$ \\
\hline
\end{tabular}

- 89.71), however its specificity was low. Impairment of vibration had the highest specificity, range of specificity 80.43 (95\% CI 67.12 - 90.01) to 85.53 (95\% CI 76.24 - 92.15). None of the physical signs alone had sufficiently high positive likelihood ratio to significantly increase the post-test probability of neuropathy with the sign being positive. Similarly none of the signs by itself had a low negative likelihood ratio to be able to rule out neuropathy (Table 3 ).

\section{Discussion}

Our study showed that of all the physical signs absent ankle reflex was highly sensitive of detecting neuropathy. Impaired vibration was specific of all the test in the clinical diagnosis of peripheral neuropathy. For the reliability of the test it was the impaired vibration that the percentage agreement was fair.

Table 3. Accuracy of Physical Signs

\begin{tabular}{|c|c|c|c|c|c|c|}
\hline Variable & Sensitivity & Specificity & LR+ & LR- & PPV & NPV \\
\hline \multicolumn{7}{|l|}{ Sensory } \\
\hline Parasthesia & $\begin{array}{l}50 \\
(36.84-63.16)\end{array}$ & $\begin{array}{l}41.3 \\
(27.82-55.86)\end{array}$ & 0.85 & 1.21 & $\begin{array}{l}50 \\
(37.1-62.8)\end{array}$ & $\begin{array}{l}41.3 \\
(28.88-55.66)\end{array}$ \\
\hline Dysthesia & $\begin{array}{l}50 \\
(30.59-69.41)\end{array}$ & $\begin{array}{l}42.11 \\
(31.40-43.40)\end{array}$ & 0.86 & 1.18 & $\begin{array}{l}21.4 \\
(12.7-33.81)\end{array}$ & $\begin{array}{l}72.72 \\
(58.15-83.65)\end{array}$ \\
\hline Impaired vibration & $\begin{array}{l}25.93 \\
(15.58-38.79)\end{array}$ & $\begin{array}{l}80.43 \\
(67.12-90.01)\end{array}$ & 1.33 & 0.92 & $\begin{array}{l}19.57 \\
(9.99-32.880\end{array}$ & $\begin{array}{l}74.07 \\
(61.21-81.42)\end{array}$ \\
\hline Impaired sensations & $\begin{array}{l}27.78 \\
(17.09-40.79)\end{array}$ & $\begin{array}{l}71.74 \\
(57.53-83.29)\end{array}$ & 0.98 & 1.01 & $\begin{array}{l}53.57 \\
(37.81-70.460\end{array}$ & $\begin{array}{l}45.83 \\
(34.82-57.26)\end{array}$ \\
\hline Absent ankle reflex & $\begin{array}{l}72.22 \\
(59.21-82.91)\end{array}$ & $\begin{array}{l}45.65 \\
(31.74-60.09)\end{array}$ & 1.33 & 0.16 & $\begin{array}{l}54.35 \\
(39.91-68.26)\end{array}$ & $\begin{array}{l}27.78 \\
(17.09-40.79)\end{array}$ \\
\hline \multicolumn{7}{|l|}{ Motor } \\
\hline Motor weakness symptom & $\begin{array}{l}63.16 \\
(47.11-77.22)\end{array}$ & $\begin{array}{l}40.32 \\
(28.69-52.84)\end{array}$ & 1.06 & 0.91 & $\begin{array}{l}59.68 \\
(47.16-71.31)\end{array}$ & $\begin{array}{l}36.84 \\
(22.73-52.89)\end{array}$ \\
\hline Absent ankle reflex & $\begin{array}{l}78.95 \\
(63.91-89.71)\end{array}$ & $\begin{array}{l}46.77 \\
(34.64-59.20)\end{array}$ & 1.48 & 0.45 & $\begin{array}{l}52.23 \\
(40.80-65.36)\end{array}$ & $\begin{array}{l}21.05 \\
(10.29-36.09)\end{array}$ \\
\hline \multicolumn{7}{|l|}{ Mixed } \\
\hline Parasthesia & $\begin{array}{l}50 \\
(30.59-69.41)\end{array}$ & $\begin{array}{l}42.11 \\
(31.40-43.40)\end{array}$ & 0.86 & 1.18 & $\begin{array}{l}21.42 \\
(12.70-33.81)\end{array}$ & $\begin{array}{l}72.72 \\
(58.15-83.65)\end{array}$ \\
\hline Dysthesia & $\begin{array}{l}66.67 \\
(46.36-83.16)\end{array}$ & $\begin{array}{l}34.21 \\
(24.22-45.39)\end{array}$ & 1.01 & 0.97 & $\begin{array}{l}65.79 \\
(54.6-75.7)\end{array}$ & $\begin{array}{l}33.33 \\
(16.84-53.64)\end{array}$ \\
\hline Motor weakness symptom & $\begin{array}{l}45.83 \\
(26.96-65.66)\end{array}$ & $\begin{array}{l}32.89 \\
(23.05-44.02)\end{array}$ & 0.68 & 1.64 & $\begin{array}{l}17.74 \\
(10.2-29.0)\end{array}$ & $\begin{array}{l}65.48 \\
(49.89-78.78)\end{array}$ \\
\hline Impaired vibration & $\begin{array}{l}25 \\
(10.81-44.92)\end{array}$ & $\begin{array}{l}85.53 \\
(76.24-92.15)\end{array}$ & 1.73 & 0.88 & $\begin{array}{l}14.47 \\
(7.85-23.76)\end{array}$ & $\begin{array}{l}75 \\
(55.08-89.18)\end{array}$ \\
\hline Impaired sensations & $\begin{array}{l}33.33 \\
(16.84-53.64)\end{array}$ & $\begin{array}{l}72.37 \\
(61.53-81.53)\end{array}$ & 1.21 & 0.92 & $\begin{array}{l}27.63 \\
(18.47-38.47)\end{array}$ & $\begin{array}{l}66.67 \\
(46.36-83.16)\end{array}$ \\
\hline Absent ankle reflex & $\begin{array}{l}75 \\
(55.08-89.19)\end{array}$ & $\begin{array}{l}43.42 \\
(32.63-54.71)\end{array}$ & 1.33 & 0.58 & $\begin{array}{l}56.58 \\
(45.29-67.37)\end{array}$ & $\begin{array}{l}25 \\
(10.81-44.92)\end{array}$ \\
\hline
\end{tabular}


Strength of the study was first, the whole spectrum of the patients (inpatient as well as outpatient) were included. Therefore there was no selection bias. Second, it was blind and independent study comparing the tests. Thirdly, the study used combination of physical signs (method of bedside examination) for diagnostic accuracy. Limitations of the study were that firstly, the under-training physicians were evaluating the patients for their physical signs. Secondly, we included all that patients who were hospitalized, therefore there was a spectrum bias and the study did not generalize to the community.

Various authors in the past have assessed clinical signs in diagnosis of diabetic neuropathy. Onde et al evaluated various methods for the clinical diagnosis of DPN which included neuropathy symptom score [NSS], the neuropathy disability score [NDS], vibration perception thresholds [VPTs], Tinel's sign and Phalen's sign. Compared with electro-physiological methods (nerve conduction studies, H-reflex and Fwave measurements), authors found significant correlations between electro-physiologically confirmed neuropathy, two provocation tests and abnormal VPTs. Authors concluded that assessment with a complete neurological examination and standard electrophysiological tests is very important for the diagnosis of diabetic peripheral neuropathy and the prevention of morbidity in patients with or without symptoms [10]. Nikoloas Papanaus et al used the neuropad test as a clinical test for the diagnosis of neuropathy in comparison to nerve conduction studies (NCS) and found that this clinical test had high sensitivity not only for the diagnosis of clinical neuropathy but also for the diagnosis of neurophysiologic neuropathy and the specificity of this test was moderately high [11].

Perkins et al in his study found the specificity and the sensitivity of all the three tests, vibration test, monofilament test and the superficial pain sensation for predicting diabetic neuropathy were similar [12].

Meijer, JW et al advised the use of vibration test with the help of tuning fork to be the better screening tool than the monofilament test and the nerve conduction sum score [13].

Cabezas-Cerrato J et al believe that the accurate diagnosis of DPN comprises a combination of clinical symptoms, signs, and several tests including $\mathrm{NCV}$, not a single reference $[14,15]$.

The current guidelines for screening of peripheral nerve dysfunction in patients with diabetes do not recommend electrophysiology as a screening tool. Current screening for neuropathy is based on clinical signs and symptoms. The International Neuropathy Guidelines define DPN as the presence of symptoms and/or signs of peripheral nerve dysfunction in people with diabetes after exclusion of other causes. To evaluate a patient for neuropathy, clinicians need to ask patients about signs and symptoms, perform a thorough physical exam, including deep tendon reflexes, motor strength and vibration, as well as perform diagnostic studies such as nerve conduction velocities (NCV). American Diabetes Association (ADA) recommends that people with diabetes should be screened annually for diabetic peripheral neuropathy, using simple tests such as pinprick sensation, vibration perception (using a $128-\mathrm{Hz}$ tuning fork), 10 -g monofilament pressure sensation at the distal plantar aspect of both great toes and metatarsal joints, and assessment of ankle reflexes, and also recommends that electrophysiological testing is rarely needed to confirm the diagnosis, although it should be used when there are atypical clinical features [16]. A systematic review assessing some of the methods advocated for preventing diabetic foot ulceration suggested that monofilaments, biothesiometer, tuning fork and peak plantar pressure were useful screening tests [17]. The results of our study however suggest that the clinical signs have only a moderate reproducibility, and have poor accuracy as compared to electrophysiological abnormalities.

Electrophysiological measures of nerve function are a more 'objective' measure for assessment of neurological deficits in diabetic patients [18]. On the other hand electrophysiology is also more technically demanding and is not universally available in primary care settings especially in developing world. It may be logical to believe that electrophysiological abnormalities precede development of clinical signs, which could have led to many false negatives, and hence a low sensitivity for most signs. On the other hand a low specificity of these signs suggests that clinical signs may also be false positive in many patients. If these findings are confirmed in future studies it will warrant a closer look at currently recommended screening strategies for diabetic neuropathy.

Electrophysiological test is not required for diabetic patients with typical symptoms of peripheral neuropathy. In an asymptomatic patient subclinical diagnosis of neuropathy can be diagnosed by changes in nerve conduction velocity on nerve conduction studies, but their presence is not predictive of the onset of symptomatic neuropathy.

Our study implies the annual foot examination of the diabetes irrespective of the duration of the diabetes. In clinical practice, however electrophysiological tests should not replace clinical examination because NCS has many pitfalls and the interpretation of the results should be done in the context of clinical data.

\section{Financial Disclosure}

No grant support was taken from any organization.

\section{References}

1. Sicree R, Shaw J, Zimmet P. Diabetes and impaired glu- 
cose tolerance. In diabetes ATLAS. 3rd Ed. Belgium, International diabetes federation, 2006;15-10.

2. Nathan DM. Long-term complications of diabetes mellitus. N Engl J Med 1993;328(23):1676-1685.

3. Dyck PJ, O'Brien PC. Meaningful degrees of prevention or improvement of nerve conduction in controlled clinical trials of diabetic neuropathy. Diabetes Care 1989;12(9):649-652.

4. Bansal R, Kalita J, Misra UK. Pattern of sensory conduction in Guillain-Barre Syndrome. Electromyogr Clin Neurophysiol 2001;41(7):433-437.

5. Herman KH, Kennedy L. For the GOAL AIC study group. Physician perception of neuropathy in a large diabetes type 2 population (GOAL AIC study) confirms underdiagnosis of neuropathy in everyday clinical practice. Diabetologia 2003;46(s2):A71.

6. Jia WP, Shen Q, Bao YQ, Lu JX, Li M, Xiang KS. [Evaluation of the four simple methods in the diagnosis of diabetic peripheral neuropathy]. Zhonghua Yi Xue Za Zhi 2006;86(38):2707-2710.

7. England JD, Gronseth GS, Franklin G, Miller RG, Asbury AK, Carter GT, Cohen JA, et al. Distal symmetric polyneuropathy: a definition for clinical research: report of the American Academy of Neurology, the American Association of Electrodiagnostic Medicine, and the American Academy of Physical Medicine and Rehabilitation. Neurology 2005;64(2):199-207.

8. Carrington AL, Shaw JE, Van Schie CH, Abbott CA, Vileikyte L, Boulton AJ. Can motor nerve conduction velocity predict foot problems in diabetic subjects over a 6-year outcome period? Diabetes Care 2002;25(11):2010-2015.

9. Veves A, Malik RA, Lye RH, Masson EA, Sharma AK, Schady W, Boulton AJ. The relationship between sural nerve morphometric findings and measures of peripheral nerve function in mild diabetic neuropathy. Diabet Med 1991;8(10):917-921.

10. Onde ME, Ozge A, Senol MG, Togrol E, Ozdag F, Saracoglu M, Misirli H. The sensitivity of clinical diagnostic methods in the diagnosis of diabetic neuropathy. J Int Med Res 2008;36(1):63-70.

11. Papanas N, Giassakis G, Papatheodorou K, Papazoglou D, Monastiriotis C, Christakidis D, Piperidou H, et al. Sensitivity and specificity of a new indicator test (Neuropad) for the diagnosis of peripheral neuropathy in type 2 diabetes patients: a comparison with clinical examination and nerve conduction study. J Diabetes Complications 2007;21(6):353-358.

12. Perkins BA, Olaleye D, Zinman B, Bril V. Simple screening tests for peripheral neuropathy in the diabetes clinic. Diabetes Care 2001;24(2):250-256.

13. Meijer JW, Smit AJ, Lefrandt JD, van der Hoeven JH, Hoogenberg K, Links TP. Back to basics in diagnosing diabetic polyneuropathy with the tuning fork! Diabetes Care 2005;28(9):2201-2205.

14. Cabezas-Cerrato J. The prevalence of clinical diabetic polyneuropathy in Spain: a study in primary care and hospital clinic groups. Neuropathy Spanish Study Group of the Spanish Diabetes Society (SDS). Diabetologia 1998;41(11):1263-1269.

15. Boulton AJ, Malik RA, Arezzo JC, Sosenko JM. Diabetic somatic neuropathies. Diabetes Care 2004;27(6):14581486.

16. American Diabetes Association (ADA). Standards of medical care in diabetes:(2009).

17. Boulton AJM. Peripheral neuropathy and the diabetic foot. The Foot 1992;2:67-72.

18. Singh N, Armstrong DG, Lipsky BA. Preventing foot ulcers in patients with diabetes. JAMA 2005;293(2):217228. 